Encuentro №. 98, 30-43, 2014

\title{
Mecanismos culturales para mantener la identidad entre los indios monimboseños de Nicaragua
}

\author{
Javier García Bresó*
}

Recibido: mayo de 2014 / Aceptado: julio de 2014

No hay culturas puras ni mezcladas, sino culturas. Cada cultura genera identidades particulares que pueden haber incorporado elementos culturales ajenos. Estos elementos forman parte del patrimonio cultural de la humanidad, pertenecen a todos los seres humanos. La etnicidad de Monimbó (Nicaragua) se fundamentó en el estigma y la marginación consecuente de su identidad india y en haber mantenido algunas tradiciones de clara influencia colonial, cuando ya en la sociedad nacional habían desaparecido. Estas incorporaciones históricamente "impuestas" constituyen ahora su base cultural más importante, una vez que sólo los indios las mantienen. Se trata de tradiciones que por supuesto han sufrido las variaciones lógicas causadas por la readaptación y el paso del tiempo, cambios impuestos que fueron apropiados, asimilados o encapsulados a través de un contacto prolongado. El fenómeno o la paradoja es: ¿Quién iba a decir que las "imposiciones culturales" contribuirían a la continuidad cultural?

Palabras clave: etnicidad / Monimbó / encapsulación / estigma / préstamo cultural

Departamento de Filosofía, Facultad de Letras, Universidad de Castilla-La Mancha (UCLM). Ciudad Real. España. Dirección postal personal: Urbanización Cañada Molina, no 138 - 16123 Arcas del Villar. Cuenca. España.Tel: 969253202. Correo electrónico: Javier.GBreso@uclm.es 


\section{Planteamiento teórico: el problema de la cultura "pura"}

Cada grupo humano desarrolla una cultura, que es el resultado de enfrentar los problemas que se presenten a lo largo de su propia existencia. Todo ello constituye el patrimonio cultural. Es importante asumir que muchas soluciones que otras culturas han conseguido para resolver sus problemas, pueden ser aplicadas para que otros también se puedan beneficiar. El desarrollo de la humanidad ha sido posible gracias al intercambio de ese patrimonio cultural. Por eso hay que asumir que "nosotros somos, también gracias a los otros", incluyendo en ser casi todas las dimensiones dentro del campo de las relaciones y reciprocidades.

En esto también subyace la idea de globalización. Siguiendo el concepto de "globalization from above" (Brecher, Brown Childs \& Cutler, 1993) - la globalización desde arriba, utilizada para denominar a los movimientos sociales transrregionales que resisten y usan las comunicaciones y las tecnologías hegemónicas - los préstamos culturales no tienen por qué anular las identidades de los pueblos, más bien todo lo contrario. Como señala James Clifford: "Las historias más antiguas de los contactos cosmopolitas discrepantes pueden fortalecer las nuevas formas del ser 'tradicional' traducidas a una escala más local” (Clifford, 1994, p. 327). Por lo tanto, deberíamos empezar a considerar que los seres humanos hemos aprendido a sacar algún tipo de beneficio del contacto intercultural. No pretendo justificar sino analizar el contacto a pesar de que haya podido ser negativo para un grupo en concreto. En todo caso, se trata de poner en tela de juicio lo que se ha denominado como "el mito de la pureza cultural" (Palladino, 2002, p. 1). Al igual que hoy no es verosimil hablar de "raza pura", tampoco lo sería hablar de "cultura pura".

Es necesario recurrir al pasado, sobre todo para suavizar las variadas opiniones que hoy se expresan constantemente en relación a la convivencia. Durante largos periodos y en muchos lugares del planeta han convivido diferentes pueblos de distintas religiones, razas, culturas y lenguas. Pero para no irnos demasiado lejos podemos centrarnos en la península ibérica y recordar el pasado, cuando en la España musulmana del siglo XI al XIII judíos, musulmanes y cristianos convivieron, comerciaron y conversaron en el proceso del mantenimiento de las distintas comunidades. James Clifford nos advierte que tampoco hay que reducir estos siglos a un multiculturalismo romántico, pero que sí es necesario reconocer una extraordinaria red cosmopolita. Goitein pudo reconstruir esta red en los seis volúmenes que escribió a partir del apoyo del rico archivo de registros comerciales, personales y religiosos desde el siglo X al XIX, que estaba en el almacén de la sinagoga de Fustat (El Cairo antiguo) (Clifford, 1994, pp. 325-332).

También Ammiel Alcalay, que respeta generosamente la visión de Goitein, presenta un mundo levantino caracterizado por las mezclas culturales, la relativa libertad para viajar, la ausencia de guetos y el multiculturalismo. O sea, la antítesis de las separaciones nacionales, raciales y religiosas. Aunque como el mismo Alcalay puntualiza, el abismo diferenciador estuvo entre hombres y mujeres (Clifford, 1994, p. 325), un tema en el que hoy cada vez se presentan más estudios, pero sobre el que aún quedan muchas perspectivas por analizar. 
Pero como se verá más adelante, en el pasaje de Ralph Linton, parece que no habría que descartar tan rápidamente el papel de la difusión en el proceso de las innovaciones tecnológicas y demás aspectos de orden social. Desde hace mucho tiempo, el difusionismo se considera una teoría obsoleta y superadísima. No voy a negar lo contrario, teniendo en cuenta las ideas expresadas en las obras de Gabriel de Tarde (2000), Ratzel (1904), Graebner (Márquez Miranda, 1941), Schmidt (1939) o Eliot-Smith (1929) a principios del siglo XX. Sin embargo, cada vez más aparecen indicios para pensar en que desde los procesos de migración, o de lo que sería algo parecido, desde los intercambios o flujos de cualquier tipo, producidos entre personas de diferentes culturas, lo que se ha entendido como difusión, en realidad no hubiera sido muy erróneo haberlo llamado globalización. Y es que los procesos migratorios son inseparables de la globalización. Según Arjun Appadurai estos procesos son uno de los flujos del mundo moderno, junto con los de orden económico, cultural, tecnológico e ideológico (CEPAL, 2006, p. 7). Pero en la antropología la difusión adquirió un cierto énfasis estigmatizante porque llevaba aparejada la idea de aculturación y, cuando más, de destrucción cultural. Dos conceptos contra los que lucharía cualquier científico social si fueran impuestos a alguna cultura.

La idea de "cultura pura" se ha difundido bajo connotaciones de "tesoro escondido". Tanto es así que incluso en la segunda mitad del siglo XX todavía se anunciaban descubrimientos de grupos humanos desconocidos. Me refiero al caso de los Tasaday de Filipinas, toda una patraña diseñada por un régimen político dictatorial que tardó más de una década en ser descubierta (Headland, 1998, pp. 8081). Fue en 1971 cuando los medios de comunicación de todo el mundo difundieron la noticia. En agosto de 1972 la National Geographic Society, a través de su National Geographic Magazine, divulgó por todas partes el descubrimiento del último grupo de trogloditas que aún vivían en las profundidades de la selva de la provincia de Kotabato Meridional, al sur de Mindanao, Filipinas. Su descubridor fue Manuel Elizalde, antropólogo y director de Panamin, un organismo del gobierno encargado de los grupos indígenas. La historia proporcionó sustanciosas ganancias a distintas personas, sobre todo al periodista John Nance por la publicación en 1975 de su libro The Gentle Tasaday: A Stone Age People in the Philippine Rain Forest (Los amables tasaday: un pueblo de la Edad de Piedra en el bosque pluvial de Filipinas). Pero en 1986 el periodista suizo Oswald Iten llegó sin anunciarse hasta donde se encontraban los tasaday y los encontró viviendo en casas y vestidos. Y la cueva, donde se dijo que era su habitación, totalmente vacía. Así empezó la controversia con opiniones encontradas entre los distintos estudiosos del asunto. Con el informe de la American Anthropological Association de 1992, editado por Thomas N. Headland y titulado The Tasaday Controversy: Assessing the Evidence (La controversia de los tasaday: evaluación de los datos), se puso fin a la patraña ideada por Elizalde.

Ese sentido de "pureza" cultural, reclamado por Rousseau en lo que llama "los progresos casi insensibles de los comienzos" (Lévi-Strauss, 1976, p. 315), es la quimera del propio Lévi-Strauss en su idea de llegar hasta el "extremo límite del salvajismo”. En su búsqueda de una sociedad reducida a su más simple expresión, y que cree encontrarla en los nambiquara y los mundé de Brasil, expresa: 
Sin embargo, esta aventura, que comencé con entusiasmo, me dejó una impresión de vacío (...) Ellos estaban allí, dispuestos a enseñarme sus costumbres y sus creencias, y yo no sabía su lengua. Tan próximos de mí como una imagen en el espejo, podía tocarlos, pero no comprenderlos. Recibía al mismo tiempo mi recompensa y mi castigo... (p. 332).

Como desde hace tiempo observó Denys Cuche (2004):

no hay de un lado culturas 'puras' y del otro culturas 'mestizas'. Todas, por el hecho universal de los contactos culturales, son en grados diversos culturas 'mixtas', hechas de continuidades y discontinuidades... Como mostró Bastide, la discontinuidad cultural debe buscarse, sin dudas, más en el orden temporal que en el orden espacial. La continuidad afirmada de una cultura dada es, con frecuencia, más ideológica que real (pp. 82 84).

Por tanto, ha de quedarnos claro que la manera de proceder del ser humano nunca ha sido estática. Nunca ha estado encerrado en su nicho ecológico y viviendo sin relaciones con personas de otras culturas, sino totalmente dinámico, inquieto, y buscando siempre y en todo momento nuevos horizontes y territorios desconocidos. Casi siempre los cladogramas o árboles genealógicos de la historia de los humanos se han presentado de formas casi lineal, y no es sostenible por más tiempo esa linealidad. Al revés, el tradicional procedimiento, para entendernos mejor, es asumir que los seres humanos "siempre hemos saltado de rama en rama", impulsados por ese mismo sentido dinámico de la esencia de la vida. Y como primates, una asociación de la que siempre queremos huir, hemos sido unos buenos saltadores. No sólo entramos en contacto con pueblos vecinos, sino que desde el origen africano se saltó al resto de continentes y así las mezclas culturales fueron inevitables.

\section{Beneficios del contacto entre culturas}

En consecuencia de lo antes planteado, el contacto entre grupos y el aprender unos de otros aquellas cosas que resultan útiles y necesarias para enfrentar los problemas de la vida misma y mejorar nuestro estado de bienestar, resulta inevitable. Incluso en el mundo académico lo hacemos con frecuencia: aprendemos de otros. También es una manera de globalizar. El conocimiento no hubiera llegado a los niveles en los que se encuentra hoy si no hubiéramos conocido las ideas del resto de intelectuales de otras tierras, de otros países, de otras culturas. El aprendizaje tiene su fundamento no sólo en lo que yo descubro del mundo sino en lo que los demás también han descubierto de él. Entonces habría que empezar a considerar con seriedad que la esencia de la vida misma ha sido trasladarse, moverse, mezclarse, en definitiva emigrar y con ello transmitir partes de lo que constituye el patrimonio cultural.

En este camino del contacto intercultural puede suceder que se inicien procesos de aculturación inevitables o intencionados, y así llegar a la no deseable pérdida cultural. Pero también los seres humanos reaccionamos utilizando mecanismos culturales para incorporar los nuevos elementos, incluso los impuestos desde afuera, 
a patrones conceptual y estructuralmente existentes en nuestros comportamientos sociales y rituales (García Bresó, 2009, p. 17).

Por regla general crecemos creyendo que las cosas que sabemos, conocemos y utilizamos constituyen el estado natural del mundo. No sólo pensamos que nos pertenecen sino que vivimos asumiendo, sin más reflexión, que son necesarias. Esto no deja de ser una de las trampas que desarrollan las culturas para legitimar nuestros diferenciados comportamientos.

Todas estas reflexiones pueden servir como introducción al tema que es objeto de este estudio. Pero primero quiero recordar un pasaje, ya clásico, de Ralph Linton, que considero muy ejemplar para comenzar a entender el "fenómeno" sobre el que quiero llamar la atención. La idea de Linton (1992), y que subraya Foster (1974, pp. 26-27), va dirigida fundamentalmente a los norteamericanos. Pretende recordarles la deuda que tienen contraída con las culturas del mundo, dice así:

Nuestro sujeto se despierta en una cama hecha según un patrón originado en el cercano Oriente, pero modificado en la Europa del norte antes de pasar a América. Se despoja de las ropas de cama hechas de algodón, que fue domesticado en la India, o de lino, domesticado en el cercano Oriente, o de seda, cuyo uso fue descubierto en China; todos estos materiales se han transformado en tejidos por medio de procesos inventados en el cercano Oriente. Al levantarse, se calza unas sandalias de tipo especial, llamadas mocasines, inventadas por los indios de los bosques orientales, y se dirige al baño, cuyos muebles son una mezcla de inventos europeos y americanos, todos ellos de una época muy reciente. Se despoja de su pijama, prenda de vestir inventada en la India, y se asea con jabón, inventado por los galos; luego se rasura, rito masoquista que parece haber tenido origen en Sumeria o en antiguo Egipto.

Al volver a su alcoba, toma la ropa que está colocada en una silla, mueble procedente del sur de Europa, y procede a vestirse. Se viste con prendas cuya forma originalmente se derivó de los vestidos de piel de los nómadas de las estepas asiáticas y calza zapatos hechos de cueros, curtidos por un proceso inventado en el antiguo Egipto, y cortados según un patrón derivado de las civilizaciones clásicas del Mediterráneo. Alrededor del cuello se anuda una tira de tela de colores brillantes, supervivencia de los chales o bufandas que usaban los croatas del siglo XVI. Antes de bajar a desayunar se asoma a la ventana, hecha de vidrio inventado en Egipto y, si está lloviendo, se calza unos zapatos de caucho, descubierto por los indios de Centroamérica, y coge un paraguas, inventado en el Asia sudoriental. Se cubre la cabeza con un sombrero hecho de fieltro, material inventado en las estepas asiáticas.

Ya en la calle, se detiene un momento para comprar un periódico, pagándolo con monedas, una invención de la antigua Lidia. En el restorán le espera toda serie de elementos adquiridos de muchas culturas. Su plato está hecho según una forma de cerámica inventada en "China". Su cuchillo es de acero, aleación hecha por primera vez en el sur de la India, su tenedor es un invento de la Italia medieval, y su cuchara un derivado de un 
original romano. Comienza su desayuno con una naranja, procedente del Mediterráneo oriental, un melón de Persia, o, quizá, una raja de sandía de África. Además doma un poco de café, planta de Abisinia, con leche y azúcar. Tanto la domesticación de las vacas como la idea de ordeñarlas se originaron en el cercano Oriente, y el azúcar se hizo por primera vez en la India. Después de la fruta y el café sigue con los waffles, que son una especie de tortillas, hechas según una técnica escandinava, con trigo, aclimatado en Asia Menor. Sobre estas tortillas desparrama un poco de jarabe de arce, inventado por los indios de los bosques orientales. Además, puede servirse unos huevos de una especie de pájaro domesticado en Indochina, o algún filete de carne de un animal domesticado en Asia Oriental, salada y ahumada según un proceso inventado en el norte de Europa. Una vez que ha terminado de comer, se pone a fumar, costumbre del indio americano, consumiendo una planta, domesticada en Brasil, ya sea en una pipa, derivada de los indios de Virginia, o en cigarrillo, derivado de México. Si es suficientemente vigoroso elegirá un puro, que nos ha sido transmitido de las Antillas a través de España. Mientras fuma lee las noticias del día impresas con caracteres inventados por los antiguos semitas sobre un material inventado en China, según un proceso inventado en Alemania. A medida que se va enterando de las dificultades que hay por el extranjero, si es consciente ciudadano conservador, irá dando las gracias a una deidad hebrea, en un lenguaje indoeuropeo, por haber nacido en el continente americano (Linton, 1992, pp. 318-319).

Indudablemente este pasaje nos hace recapacitar sobre las adquisiciones culturales que todas las sociedades han ido recibiendo a través del tiempo, sin sufrir por ello alteraciones o transfiguraciones profundas en su cultura total. En todo caso han contribuido a que la idea de progreso se afiance cada vez más en las sociedades receptoras. Pero de ninguna manera estas adquisiciones han puesto en peligro su continuidad cultural. Pensar que estos cambios se han impuesto siempre por la fuerza desde una sociedad dominante a otra dominada no es la mejor forma de entender el contacto intersocial. Muchas sociedades europeas han dominado a otras también europeas a lo largo de la historia. Y no se puede decir que el producto de estas dominaciones haya sido la imposición total de la cultura dominante. De ser así no podríamos hablar de las varias culturas del continente europeo que hoy existen, incluso dentro de un mismo país.

La dominación también genera resistencia, que en muchos casos puede llegar a ser hasta endémica, incluso a veces, como señala Bonfil Batalla (1981, p. 239), convierte al conservatismo en actitudes profundamente subversivas, que garantizan la negación radical de la dominación. No es fácil “imponer” elementos de una cultura a otra. Lo mismo que tampoco es difícil que en una situación de contacto prolongado todos los miembros de una sociedad sigan los mismos patrones de reacción. Parece ser que en sociedades sin clases la respuesta tiende a afectar a toda la sociedad, mientras que en sociedades con una organización de clases bien desarrollada, probablemente, no todas las clases reaccionarían de la misma forma (Spicer, 1971, pp. 335-336). 
Las circunstancias que envuelven a cada caso no dejan de ser bastante particulares y evitan que puedan establecerse generalizaciones,que midan con el mismo rasero las respuestas no sólo de cada grupo sino de cada sector o miembros que componen el mismo grupo. También debe considerarse que las imposiciones por la fuerza en periodos de dominación conducen a una mayor violencia y rechazo en el estado del contacto.

En contrapartida, los cambios más sustanciales y mejor aceptados pueden producirse cuando la relación dominador/dominado ha sido enmascarada bajo una configuración amistosa. Entonces las motivaciones para el cambio alcanzan mejores condiciones para llevarse a cabo y pueden ser estimuladas a través de aspectos como: el deseo de prestigio, el deseo de ventajas económicas, la situación de competencia, los compromisos de amistad, la motivación del gusto y del pasatiempo, y los motivos religiosos (Foster, 1974, pp. 140-155).

\section{Particularizando el patrimonio cultural}

No se centra mi interés en hablar del cambio en general, sino de una fórmula o estrategia bastante especial que poseen las culturas para asimilar determinados elementos que provienen de afuera sin que sufran por ello pérdidas importantes en su conjunto cultural. El pasaje de Ralph Linton (1992) parece sugerirnos que las culturas occidentales, concretamente la norteamericana, se ha constituido a base de préstamos culturales. Una aplicación semejante podríamos establecer con la cultura española en general o con la francesa, italiana, inglesa, etc. Siempre podrán destacarse elementos culturales en mayor o menor cantidad cuyo origen y primera elaboración proviene de otros lugares, de otras culturas. Estos elementos han sido apropiados, asimilados, aceptados, encapsulados, readaptados y también rechazados desde sus formas primitivas. Sin embargo, no por ello estas culturas han dejado de existir. Ni siquiera se han tambaleado sus cimientos. Desde luego que han sufrido cambios a través de su historia, pero el cambio cultural es un fenómeno universal, es la forma de ser de las culturas, no su negación (Bonfil Batalla, 1981, p. 22).

Tal vez algo que a Ralph Linton (1992) le ha faltado exteriorizar de una manera más expresiva y directa es la variación que desde su origen se ha imprimido sobre esos "préstamos culturales". A muchos nos cuesta trabajo pensar que nuestras camas, vestidos, cubiertos, zapatos, sombreros, productos alimenticios, paraguas, monedas, cigarrillos, etc. no nos pertenecen. Abiertamente yo protestaría si me dicen que el "zapato castellano", fabricado en Elche (Alicante, Comunidad Valenciana) no es un elemento original de las regiones castellanas (Comunidades Catellano-Manchega y Castellano-Leonesa). Asimismo, me sorprende más mirar a un indonesio con un paraguas negro que a un español, cuando en realidad ahora descubrimos que es un invento del Asia Sudoriental. Frente a estas situaciones debo preguntarme, ¿por qué sucede esto así? ¿por qué estos instrumentos que originalmente no pertenecen a la cultura de la cual procedo, los siento como propiedad de ella? Indudablemente porque se han producido adquisiciones y apropiaciones culturales que han permitido adquirir el control de estos elementos de origen ajeno (Bonfil Batalla, 1985, p. 142). 
Durante los años sesenta del siglo XX a los japoneses se les endosó, merecida o inmerecidamente, el estereotipo de "copiadores industriales". Sin embargo, el invento original francés de la cámara fotográfica resulta muy difícil no identificarlo hoy con los japoneses. A partir de su apropiación adquirieron su control y perfeccionaron algo que ahora sí les pertenece y que les identifica. En caso de que el desarrollo pueda considerarse como una necesidad para la cultura de una sociedad, es posible que el de muchas sociedades no haya avanzado suficientemente porque les ha faltado adquirir estos elementos.

Pues bien, seguidamente me referiré - en este sentido expuesto de que una cultura es capaz de apropiarse, asimilar, readaptar o encapsular y controlar elementos culturales de origen ajeno - a una comunidad india de la costa del Pacífico en Nicaragua. Extraeré ejemplos de adquisiciones culturales de un grupo indio que ha permanecido bajo la influencia colonial española, y analizaré lo que han supuesto estas adquisiciones para el conjunto de su cultura. Un caso en cierto grado parecido nos lo presenta Arthur G. Miller (1991, p. 141) cuando analiza las transformaciones del tiempo y del espacio en los mapas y calendarios zapotecos de Oaxaca, México. La introducción de sistemas simbólicos europeos y modos de representación en México durante la primera parte del siglo XVI provocó una gran variedad de procesos interactivos de cambio que afectaron al recuerdo, a la cognición y a la producción mexicana de imágenes y textos. Así los zapotecos incluyeron el alfabeto latino y los números arábigos para realizar sus calendarios rituales. Camuflaron de esta manera la práctica de sus tradiciones culturales de origen prehispánico ante los colonizadores españoles, que se las habían prohibido (Miller, 1991, p. 143).

Mi exposición, implícitamente, aunque el ejemplo tenga que ver con España y América, en realidad debería aplicarse también a las culturas que han entrado en contacto a partir de un momento específico de la historia. En ellas el cambio cultural reviste características particulares, determinadas por la condición de las culturas oprimidas. Participo de la opinión que desde hace mucho tiempo Guillermo Bonfil Batalla ha dejado explícita y en la que además señala que "los grupos indios que han estado sujetos a la dominación colonial han hechos suyos, de buen grado o por la fuerza, muchos elementos de origen occidental; pero la aculturación no significa 'desindianización' ni pérdida de identidad en términos del grupo étnico" (Bonfil Batalla, 1981, p. 22). No voy a incidir en problemas más complejos que hablan de destrucción, sólo de lo que he encontrado en mi investigación en tierras nicaragüenses.

\section{Procesos y mecanismos para mantener la identidad étnica en Monimbó}

Aunque desde España, o cualquier otro país, posiblemente los indios más conocidos de Nicaragua sean los Mískitos de la Costa Atlántica, hay que comenzar diciendo que existen otras comunidades indígenas tanto en la misma Costa Atlántica como en la del Pacífico. En este sector y a unos treinta kilómetros al sur de Managua, hay una ciudad de arquitectura muy colonial que se llama Masaya. En esta capital departamental o provincial existe un barrio, que siempre se ha conocido como el 
Barrio Indígena de Monimbó. Éste se extiende fuera de la ciudad hacia las ricas y fértiles laderas de un antiguo, pero enorme, volcán erosionado.

A pesar de la ausencia directa de rasgos culturales contrastantes, los monimboseños se reconocen como indios y el resto de Masaya también los considera como tales. Su etnicidad se fundamenta no sólo en el estigma (Lavallé,1990, pp. 319-342) y la marginación (Gould, 1997, pp. 128-129) consecuente de su identidad, sino en haber mantenido algunas tradiciones de clara influencia colonial con un arraigo y apego especial, cuando ya en la sociedad nacional han desaparecido. Por esto se suele decir que "Monimbó es la cuna del folklore nicaragüense".

A pesar de los variados procesos de estigmatización (García Bresó, 2009, pp. 368-369) que se han llevado a cabo con respecto a la cultura monimboseña, que reflejan el desprecio y la humillación a través de aforismos, dichos, cuentos o refranes, el principal estigma sobre los indios ha recaído en su pobreza. Las distintas políticas institucionales han acabado logrando que en muchos casos el indio se incluya dentro del sistema de clases (si bien su lucha siempre se ha caracterizado por la búsqueda de un espacio cultural propio, ajeno a este sistema) como la clase social más baja y más pobre en la estructura nacional. Esta situación de pobreza material, en términos absolutos pero también en términos relativos, consiste no solamente en no tener lo suficiente para vivir como necesitamos vivir, sino en no tener lo que otros tienen. Y esto viene a sumarse a la acusación de pobreza también cultural, que lleva a considerar a los indígenas como gente incivilizada, sin cultura. Ambas situaciones generan un fuerte desprecio por parte de la sociedad dominante, que rechaza lo indígena como inferior y convierte en símbolo de prestigio todo lo propio. Así, las personas que han conseguido elevar su nivel de vida tienden a pasar por alto la identidad étnica. Quizá por eso, también, cuando los salesianos construyeron, con la ayuda de los monimboseños, una escuela en el barrio, destinaron un local anexo para uso exclusivo de los indígenas, mientras que el resto de la población de Masaya ocupó el edificio principal.

El indio se ve obligado a protegerse de la humillación estableciendo fronteras (Bengoa, 2007, p. 90) y acumulando odios silenciosos que no pueden manifestarse de otra forma más que con la indiferencia ante todo lo que viene del blanco, que por otra parte no es mucho referido a lo bueno y no es poco referido a lo malo. El estigma hace que el desprecio o la indiferencia se conviertan en mutuo, estableciéndose de esta forma sólidas fronteras culturales que se perpetúan en el tiempo.

Las incorporaciones históricas de los monimboseños en un principio alteraron su tecnología, sus formas de ordenamiento social y su visión del mundo. Todo ello fue efecto de la conjunción con una sociedad más avanzada y en condiciones de subordinación. Y esto les condujo a la pérdida de la autonomía en el manejo de su destino (Ribeiro, 1971, p. 11). Sin embargo, ahora estas tradiciones constituyen la base cultural más importante de los indios, una vez que sólo ellos las mantienen y aunque, por supuesto, hayan sufrido las variaciones lógicas de la readaptación y del paso del tiempo. En estos cambios impuestos pudieron ayudar factores casuales como el deseo de prestigio y los motivos religiosos, y poco a poco fueron apropiados, asimilados o encapsulados a través de un contacto prolongado.

Estos cambios afectaron a ciertas formas de organización comunitaria, como por ejemplo a los cabildos indígenas, a los sistemas de cargos administrativos 
y religiosos, y sobre todo, a su sistema de fiestas. Pero el hecho de que aún hoy persistan de una forma particular, constituye una clara evidencia de su continuidad cultural. También se puede observar en ello un proceso, como señala Darcy Ribeiro (1971, pp. 10-13), de transfiguración étnica en el que las poblaciones tribales que se enfrentan con sociedades nacionales llenan los requisitos necesarios para su persistencia como entidades étnicas mediante alteraciones sucesivas en su sustrato biológico, en su cultura y en sus formas de relación con la sociedad envolvente.

A mi juicio, quien mejor ha expresado este proceso ha sido Evon Z. Vogt con la palabra "encapsulación”. Este concepto puede sugerir otras imágenes mentales, pero Vogt lo define con mucha precisión. Dice que: "la encapsulación es un proceso en el que nuevos elementos impuestos desde afuera son conceptual y estructuralmente incorporados a patrones existentes de comportamiento social y ritual" (Vogt, 1979, pp. 281-284). Con este concepto deja muy sentado que una cultura posee mecanismos para evitar su destrucción paulatina, propiciada por los agentes externos que presionan sobre ella. Este fenómeno puede ser visto también como una especie de sincretismo que las culturas desarrollan con el fin de enfrentar nuevos elementos inyectados en su forma de vida.

En virtud de estos procesos encapsuladores o de este modelo de comportamiento inherente en todos los seres humanos, los indios monimboseños han reelaborado su propia configuración cultural. Ahora ya, paradógicamente las imposiciones culturales del pasado se han convertido en tradiciones que les identifican. Sin importar su origen ni cómo fueron impuestas, son consideradas auténticamente suyas porque son ellos mismos quienes al mantenerlas y readaptarlas las han introducido en su mundo y ahora se distinguen por ellas.

Quiero señalar como parte de estas tradiciones la referencia al Cabildo Indígena que en Monimbó se denomina Alcaldía de Vara, como también fue denominado en el pasado y en muchos otros lugares de América porque al Alcalde Indígena elegido se le entregaba, al tomar posesión y como símbolo de su poder, una "vara de mando" (Pozas \& de Pozas, 1980, pp. 87-91). Este símbolo se sincretizó con las macanas o bordones que utilizaban los caciques mayores y menores como distintivos de su rango y clan. La nueva forma sólo varió la representación clánica que se situaba en la parte superior de la vara donde reproducían cabezas de animales hechas con diferentes tipos de piedras o arcilla. Ahora el nuevo símbolo se reducía a una esfera con una cruz encima, un claro atributo de las monarquías europeas. Este modelo de vara de mando se mantuvo, pero las funciones administrativas, religiosas, económicas y judiciales propias del cargo fueron modificándose en el proceso de los cambios estructurales, políticos y jurídicos que sufrió el país al pasar de la etapa colonial a la independencia.

Lógicamente no se puede negar que estas modificaciones procedieran del mundo exterior y que cada grupo indio quedara a merced de estos cambios. Quizás muchas comunidades indias perdieron su status por esta causa. Sin embargo, los monimboseños, a pesar de la reducción de funciones de la Alcaldía de Vara, han mantenido esta institución hasta la actualidad sin perder el vínculo de representación comunitaria que aún posee. El Alcalde Indígena no ejerce las mismas funciones que en otros tiempos porque los sucesivos gobiernos han hecho inútil su papel. Pero el grupo sí ha preservado en esta autoridad algunas actividades que 
refuerzan su vigencia. No sólo se ocupa de controlar la última propiedad de la comunidad, qiue son los cementerios, sino que como dicen en Monimbó "cuando el bongo (tambor) del Alcalde suena, Monimbó se oye”, refiriéndose tanto a la capacidad de convocatoria como al respaldo que se le da a esta figura ante los problemas comunales.

Se podría hablar de otros muchos ejemplos de encapsulación sobre esta comunidad india de Monimbó, pero para no extenderme demasiado sólo me referiré ligeramente al sistema de cargos y fiestas religiosas. En éstas se expresa mejor la asimilación de elementos culturales de origen ajeno. Las cofradías han ejercido un papel muy significativo para la vida comunitaria, sobre todo a partir de la colonización, ya que la exclusión de los indios de la vida social cosmopolita (Smith, 1981, p. 13) les ha impedido participar en las decisiones de poder. Por tanto, las cofradías han posibilitado la única alternativa de organización social en la propia comunidad. Como única forma organizativa, los indios encapsularon o se apropiaron para sus cargos en las cofradías, de los nombres y rangos de los cabildos coloniales. De ahí que palabras como Prioste, Alférez, Alguacil, Teniente, Mayordomo, etc. traten de reproducir los órganos de poder colonial. Estos cargos, sincretizados con las fórmulas antiguas de organización indígena, permanecen en muchas comunidades indias de América. Sin embargo, en Monimbó estos títulos, que ocupan personas de una manera temporal, han sido ampliados con nuevas adquisiciones no sólo de la vida social moderna - como secretario, coordinador, contable o administrador - sino también de la vida anterior de los indios que fue escrita por el cronista Gonzalo Fernández de Oviedo, como Consejo de Ancianos y Principales.

La historia narrada también puede ser una fuente de encapsulación cuando en ciertos momentos históricos a los indios se les "deja respirar" y se les valora como sucedió en la década de 1980 durante el gobierno sandinista que, además, también utilizó lo étnico como símbolo de rebeldía social contra el poder colonial o extranjero.

Las agrupaciones y cofradías donde se han producido estas adquisiciones o apropiaciones son las del Torovenado del Pueblo y otros Torovenados, la de San Sebastián y sus variadas mayordomías, la de las Ánimas, la del Domingo de Lázaro, la del Señor de los Milagros, las mayordomías del Niño Dios, etc.

\section{Conclusión}

Todo este discurso nos conduce a plantearnos un último interrogante: ¿es suficiente el mecanismo de la estigmatización para deshacer la identidad étnica? En realidad es un control social no institucionalizado muy fuerte que obliga a las personas a ocultar lo que les humilla. Resulta bastante lógico dentro del comportamiento humano que exista la tendencia a encubrir u omitir aquello que nos ofende. Esta situación puede llevar a la persona a querer "dejar de ser lo que es", a olvidar o enmascarar siempre que pueda la identidad que lo desacredita. En este sentido los "símbolos de estigma" actuarán como "desidentificadores" y probablemente con el paso del tiempo la identidad étnica puede haber desaparecido (Goffman, 1986). Digo "puede" porque no cabe duda de que todo proceso desetnizador es lento o debe ser lento, su aceleración provocaría reacciones demasiado violentas y 
haría necesaria la intervención de la fuerza de las armas. Sin embargo, esa lentitud también puede favorecer que los "símbolos de prestigio" que la "otra" sociedad ofrece sean incorporados y readaptados a su cultura sin que se produzca la pérdida de la identidad étnica. Esto ocurre incluso a pesar de haberse añadido la identidad local, si es un barrio, y la identidad nacional. El grado de homogeneidad cultural alcanzado no siempre significará la pérdida de la identidad étnica porque también la estigmatización, que impulsa al hombre a adquirir los símbolos de prestigio, establece barreras infranqueables entre el etnocentrismo dominador y la inferioridad asumida por el dominado, en cuyo interior late un odio apagado y que puede encenderse en situaciones extremas. Zygmunt Bauman ha incluido estos procesos bajo el concepto de "modernidad líquida" (Bauman, 2004, pp. 7-20). La identidad étnica se puede considerar como un proceso que fluye entre lo líquido y lo sólido. Es una construcción cultural que el sujeto refunde con flexibilidad en el tiempo, enfrentando las distintas mutaciones a lo largo de la vida.

Viene a producirse, también, algo así como lo que Pellizzi (Pellizzi, 1982, pp. 13-14) ha denominado "separación interiorizada", refiriéndose a las sociedades fracturadas con fuerte grado de aculturación, como el ejemplo de Irlanda, en donde la aculturación profunda no elimina ni la identidad ni la fractura. Identidad y fractura se realimentan y nutren recíprocamente, lo que permite al grupo mantener su identidad de una forma latente en momentos de represión e intensificarla en momentos favorables. Esta idea de Pellizzi tiene un precedente en lo que Darcy Ribeiro (1971) conceptualizó como "transfiguración étnica”:

Un proceso a través del cual las poblaciones tribales que se enfrentan con sociedades nacionales llenan los requisitos necesarios para su persistencia como entidades étnicas, mediante alteraciones sucesivas en su sustrato biológico, en su cultura y en sus formas de relación con la sociedad envolvente" (pp. 10-13).

Este concepto también ha inspirado a Tomás Calvo Buezas (1986, p. 53) que lo ha denominado como "recreación cultural", en el que expresa la matización de que la muerte de una cultura no significa siempre la pérdida de la identidad étnica sino que ésta puede mantenerse o revitalizarse por la referencia mítico-simbólica a la antigua cultura ancestral, ya muerta o totalmente transformada. Sin embargo, en el mantenimiento de la identidad, como señala Spicer (1971, p. 41), no siempre es necesario que el grupo posea una particular y distintiva forma de vida. Un ejemplo de lo dicho también se puede observar en las identidades regionales existentes en España.

En conclusión, el problema sobre el que quiero llamar la atención, y del cual Monimbó ejemplifica su proceso, se complementa con estas argumentaciones mencionadas. La idea que se pretende expresar es que la identidad étnica es un fenómeno cultural sometido a fluctuaciones en el tiempo, cuyo mayor o menor grado de manifestación depende de la presión que ejerza sobre ella la cultura dominante. Pero además, las culturas no sólo se hayan abocadas a su desaparición desde que el contacto se produce, sino que dependiendo de la naturaleza de este contacto, pueden mantenerse a pesar del empleo de procesos desetnizadores, 
mecanismos de estigmatización o del grado de aculturación alcanzado. La identidad que configura una cultura puede mantenerse, aunque a veces sea sufriéndola, en virtud de otros mecanismos de defensa como la encapsulación, la transfiguración étnica, la recreación cultural, la separación interiorizada o la modernidad líquida como un modelo especial de globalización.

\section{Referencias bibliográficas}

Bauman, Z. (2004). La modernidad líquida. Buenos Aires: Fondo de Cultura Económica.

Bengoa, J. (2007). La emergencia indígena en América Latina. Santiago de Chile: Fondo de Cultura Económica.

Bonfil Batalla, G. (coord.) (1981). Utopía y revolución: El pensamiento político contemporáneo de los indios de América Latina. México: Nueva Imagen.

Bonfil Batalla, G. (1985). Los pueblos indios, sus culturas y políticas culturales. Anuario Indigenista (III), XLV, 129-158.

Brecher, J. Brown Childs, J. \& Cutler, J. (eds.) (1993). Global Visions: Beyond the New World Order. Boston, Massachusetts: South End Press.

Calvo Buezas, T. (1986). El grito de los chicanos en los Estados Unidos: Un movimiento de revitalización cultural. Indigenismo, 7, 52-58.

CEPAL [Comisión Económica para América Latina y el Caribe]. (2006). Migración internacional, derechos humanos y desarrollo en América Latina y el Caribe. (LG/G. 2303-SES. 31/11), 9 de marzo, Trigésimo Primer Periodo de Sesiones. Montevideo, Uruguay: Autor.

Clifford, J. (1994). Diaspora. Cultural Anthropology , 9 (3), 302-338.

Cuche, D. (2004). La noción de cultura en las ciencias sociales. Buenos Aires: Nueva Visión.

Elliot Smith, G. (1929). The Migrations of Early Culture: A Study of the Significance of the Geographical Distribution of the Practice of Mummification as Evidence of the Migration of Peoples and the Spread of Certain Customs and Beliefs. Manchester: University Press.

Foster, G. M. (1974). Las culturas tradicionales y los cambios técnicos. México: Fondo de Cultura Económica.

García Bresó, J. (2009). La conciencia de los marginados. Etnicidad en Nicaragua: Monimbó. Quito: ABYA-YALA.

Goffman, E. (1986). Estigma: La identidad deteriorada. Buenos Aires: Amorrortu Editores.

Gould, J. L. (1997). El mito de "La Nicaragua Mestiza" y la resistencia indígena, 18801980. San José, Costa Rica: Editorial de la Universidad de Costa Rica.

Headland, T. N. (1992). The Tasaday Controversy: Assessing the Evidence. Washington, D. C.: American Anthropological Association.

Headland, T. N. (1998). Los Tasaday: ¿Trogloditas de la Edad de Piedra o la patraña mejor urdida de la historia de la ciencia. En G. Burenhult (ed.). Pueblos de la tierra. (pp. 80-81). Barcelona: RBA Publicaciones, S. A.

Lavallé, B., (1990). Del indio al criollo: Evolución y transformación de una imagen 
colonial. En Consejo Superior de Investigaciones Científicas (ed.). Imagen del Indio en la Europa Moderna. (pp. 319-342). Sevilla: Publicaciones de la Escuela de Estudios Hispano-Americanos de Sevilla.

Lévi-Strauss, C. (1976). Tristes trópicos. Buenos Aires: Editorial Universitaria de Buenos Aires.

Linton, R. (1992). Estudio del hombre. México: Fondo de Cultura Económica.

Márquez Miranda, F. (1941). Fritz Graebner y el método etnológico. La Plata: Universidad Nacional.

Miller, A. G. (1991). Transformations of Time and Space: Oaxaca, Mexico, circa 1500-1700. En S. Küchler \& W. Melion (ed.). Images of Memory: On Remembering and Representation. (pp. 141-175). Washington y Londres: Smithsonian Institution Press.

Nance, J. (1975). The Gentle Tasaday: A Stone Age People in the Philippine Rain Forest. New York and London: Harcourt Brace Jovanovich.

Palladino, J. P. (2002). Sociedades multiculturales. Revistateina, (3), 1-5.

Pellizzi, F. (1982). Misioneros y cargos: notas sobre identidad y aculturación en los Altos de Chiapas. América Indígena, XLII (1), 7-33.

Pozas, R. \& de Pozas, I. (1980). Los indios en las clases sociales de México. México: Siglo XXI.

Ratzel, F. (1904). The History of Mankind. London and New York: MacMillan \& Company.

Ribeiro, D. (1971). Fronteras indígenas de la civilización. México: Siglo XXI.

Schmidt, W. (1939). The Culture Historial Method of Ethnology: The Scientific Approach to the Racial Question. New York: Fortuny's.

Smith, W. R. (1981). El sistema de fiestas y el cambio económico. México: Fondo de Cultura Económica.

Spicer, E. H. (1971). La reacción de los indios al contacto europeoamericano. América Indigena, XXXI (2), 336-35.

Tarde, G. de. (2000). Social Laws: An Outline of Sociology. Kitchener, Ontario: Batoche.

Vogt, E. Z. (1979). Ofrendas para los dioses: Análisis simbólico de rituales zinacantecos. México: Fondo de Cultura Económica. 